\title{
Rancang Bangun Sistem Informasi Manajemen Data Mahasiswa Dan Dosen Terintergasi
}

\author{
Elgamar Syam \\ Program Studi Teknik Informatika, Fakultas Teknik, Universitas Islam Kuantan Singingi \\ Email : elgamar@uniks.ac.id
}

\begin{abstract}
The development of information and management systems at universities is very important. This is due to the increasing needs and complete attributes of each component related to academic affairs in universities. Students and Lecturers are primary data in academic. Therefore, the need for good data management and governance in order to deliver accurate information, transparency, accountability and up to date. Through the design and development of student and lecturers data management information system by applying the SDLC (Software Development Life Cycle) model, resulting in a system capable of replacing or improving the old system. This information system can certainly provide description and formulation to the leadership in the application of policies to students and lecturers.
\end{abstract}

Keywords: management information system, SDLC, academic.

\begin{abstract}
Abstrak
Pembangunan sistem informasi dan manajemen pada perguruan tinggi merupakan hal yang sangat penting. Hal ini dikarenakan semakin tingginya kebutuhan dan komplitnya atribut dari setiap komponen yang berkaitan dengan urusan akademik di perguruan tinggi. Mahasiswa dan Dosen merupakan data primer dalam akademik. Oleh sebab itu, perlu manajemen data dan tata kelola yang baik agar penyampaian informasi menjadi akurat, transparansi, akuntabilitas dan up to date. Melalui perancangan dan pembangunan sistem informasi manajemen data mahasiswa dan dosen dengan menerapkan model SDLC (Software Development Life Cycle), sehingga menghasilkan sistem yang mampu menggantikan atau memperbaiki sistem yang lama. Sistem informasi ini tentunya dapat memberikan gambaran dan perumusan pada pimpinan dalam penerapan kebijakan-kebijakan terhadap mahasiswa dan dosen.
\end{abstract}

Kata kunci : Sistem Informasi Manajamen, SDLC, Akademik.

\section{PENDAHULUAN}

Pemanfaatan teknologi dalam urusan tata kelola suatu perguruan tinggi memiliki peran yang sangat penting, sehingga hal yang berkaitan dengan data-data perlu dimanajemen dengan baik menggunakan teknologi yang tepat guna, kemudian di olah dan menghasilkan informasi yang bermanfaat bagi institusi dan masyarakat luas. Tujuan dari penataan dan pengelolaan menggunakan teknologi agar mampu menghasilkan informasi yang akurat, transparan, dan akuntabilitas serta bentuk profesionalisme dalam bekerja. 
Universitas Islam Kuantan Singingi (UNIKS) merupakan salah satu institusi pendidikan yang berada pada Kabupaten Kuantan Singingi di Propinsi Riau, yang telah berdiri sejak tahun 2013 dan menjadi satu-satunya perguruan tinggi yang ada di Kabupaten Kuantan Singingi. Terbilang masih barunya perguruan tinggi ini, maka masih banyak hal yang harus diperbaiki dalam manajemen dan pengelolaannya. Hal ini dikarenakan, perguruan tinggi merupakan suatu institusi yang harus memiliki tingkat manajemen data yang baik. Adapun salah satu yang harus diperbaiki adalah sistem informasi manajamen data dosen dan mahasiswa.[1]

Perguruan tinggi memiliki data primer berupa data dosen dan mahasiswa yang mesti tepat dan akurat. Sementara, atribut dari data dosen dan mahasiswa yang sangat komplit, sehinga mengharuskan institusi perguruan tinggi merancang sebuah sistem yang mampu mengatasi permasalahan-permasalahan yang akan muncul, seperti timbulnya kerancuan pada data, adanya data yang tidak lengkap, sulitnya menemukan data yang ingin dicari serta masalah yang lainnya.[2] Dilihat dari pentingnya pengelolaan data yang baik dalam sebuah institusi, agar tidak muncul permasalahan-permasalahan yang dapat menghambat efektifitas kinerja, maka diperlukan sebuah sistem yang dirancang dan dibangun menggunakan sebuah bahasa pemrograman, sehingga terciptanya sebuah sistem yang mampu menyajikan informasi mengenai data mahasiswa dan dosen secara tepat dan akurat. Serta memudahkan Dekan dan Ketua Program Studi untuk mengetahui biodata dan jumlah mahasiswanya, dan juga memudahkan administrator (BAKASI) dalam pelaporan data mahasiswa dan dosen kepada pimpinan perguruan tinggi.[5]

\section{METODE PENELITIAN}

Penulis menggunakan model SDLC (Software Development Life Cycle) sebagai acuan, mengingat model SDLC merupakan metodologi umum dalam siklus pengembangan sistem dan merupakan penyusunan suatu sistem yang baru untuk menggantikan sistem yang lama dengan atau memperbaiki sistem yang sudah ada.[3][4]

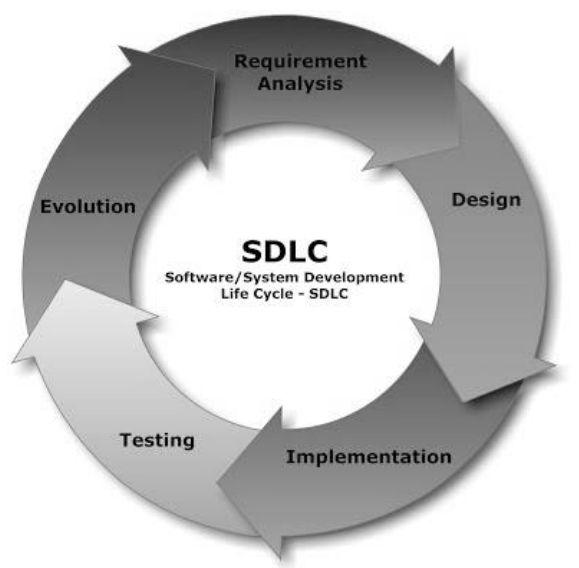

Gambar 1. SDLC Model

\subsection{Rancangan Penelitian}

Penelitian ini dirancang melalui beberapa tahapan atau prosedur, sebagai berikut : 


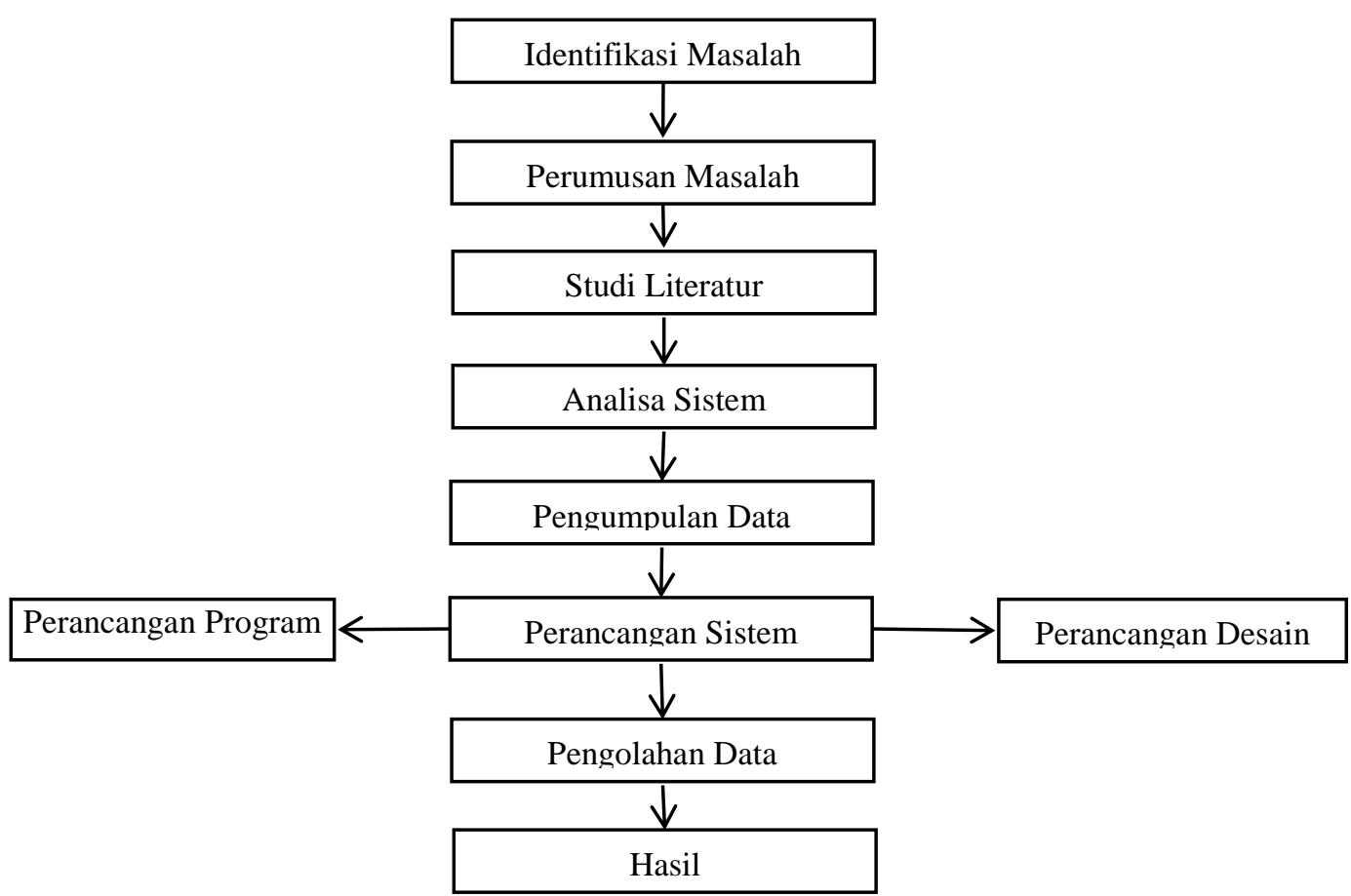

\subsection{Teknik Pengumpulan Data}

Gambar 2. Tahapan Penelitian

Salah satu faktor penting dalam pembangunan/pengembangan sistem informasi ialah memahami sistem yang ada dan permasalahannya. Adapun uraian secara konkret dari teknik pengumpulan data penelitian ini akan diuraikan sebagai berikut :

1. Teknik Wawancara

Langkah pertama yang harus dilakukan dalam proses pembangunan maupun pengembangan sistem informasi adalah mengidentiifikasi kebutuhan sistem, menganalisis situasi yang ada dan menemukan masalah yang nyata dan dengan bersamaan menghubungkannya dengan penyebab masalah tersebut. Teknik Wawancara adalah salah satu cara yang paling baik yang bisa digunakan untuk kegiatan ini.

2. Teknik Observasi

Pengamatan langsung atau observasi merupakan teknik pengumpulan data dengan langsung melihat kegiatan yang dilakukan oleh user. Salah satu keuntungan dari pengamatan langsung/observasi ini adalah bahwa sistem analisis dapat lebih mengenal lingkungan fisik.

3. Studi Pustaka

Studi pustaka dilakukan guna mendapatkan data-data yang bersifat teoritis, maka dengan itu penulis melakukan pengumpulan data dengan cara membaca dan mempelajari literatur seperti buku-buku, makalah ataupun referensi lain yang relevan dengan masalah yang dibahas. 


\section{HASIL DAN PEMBAHASAN}

Berdasarkan analisa sistem dan pengumpulan data yang dilakukan, maka pendataan Mahasiswa dan Dosen melalui sistem informasi mampu membantu admin (BAKASI), Dekan dan Ketua Prodi dalam memperoleh data yang akurat.

1. Pada halaman login terdapat 3 level yang digunakan untuk masuk kedala sistem, level 1 "administrator", level 2 "Dekan" dan level 3 "Ketua Prodi”. Pada setiap level memiliki hak akses yang berbeda, hak akses full diberikan kepada administrator.

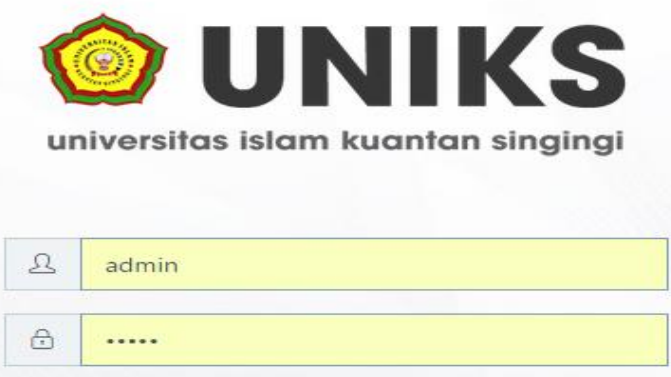

$\oplus$ Login

Gambar 3. Form login

2. Setelah login melalui administrator, maka terlihat pada interface administrator yang menyajikan seluruh informasi tentang data Mahasiswa dan Dosen. 


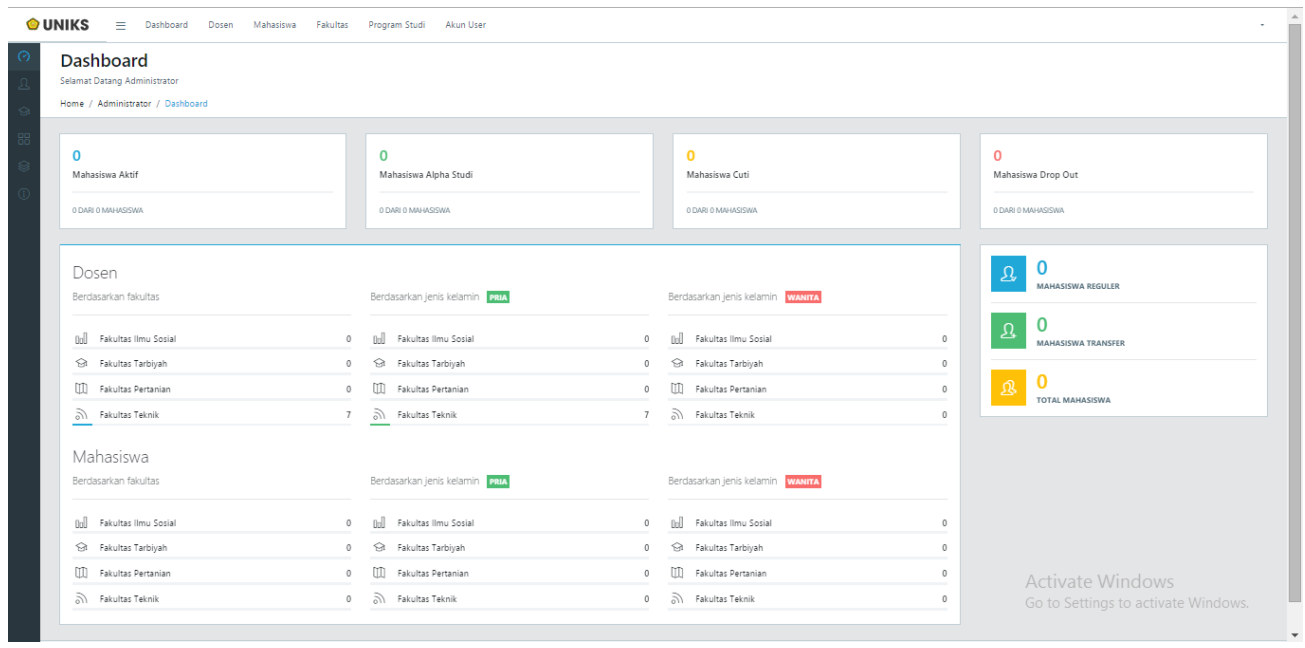

Gambar 4. Dashboard (menu informasi administrator)

3. Menu data Dosen memperlihatkan deskripsi dari data dosen itu sendiri.

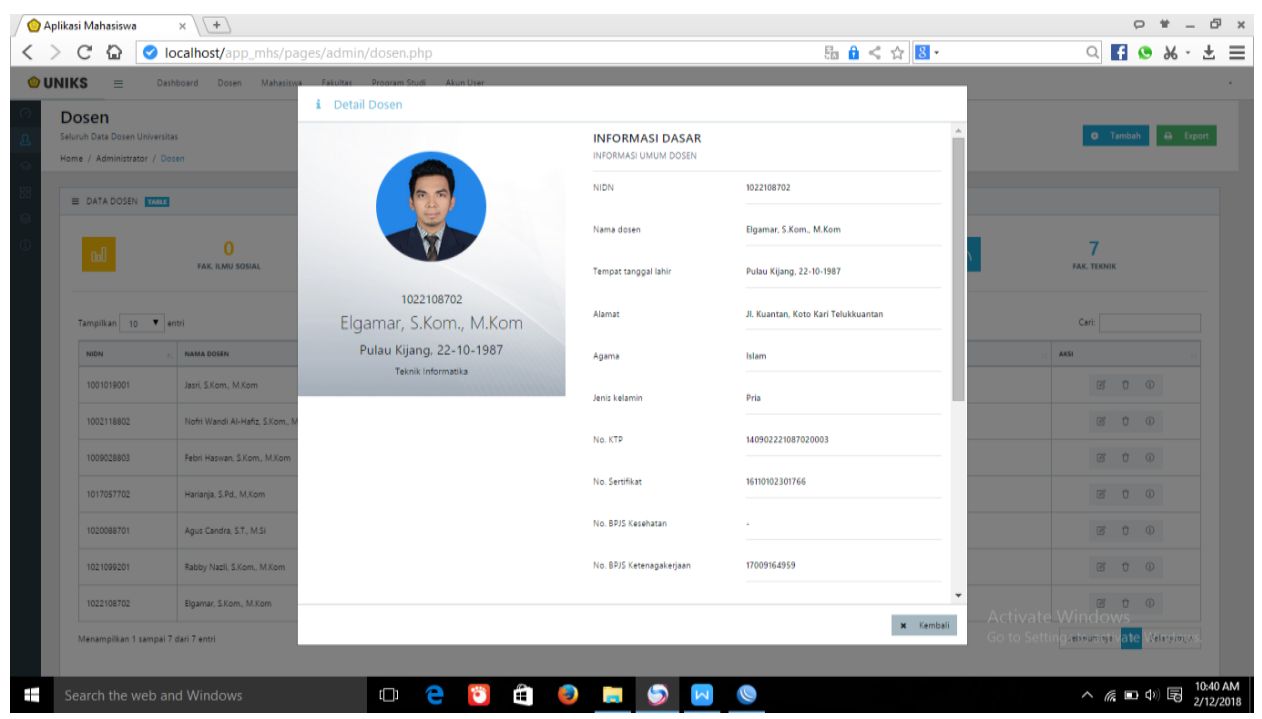

Gambar 5. Profile Data Dosen

4. Menu Entry data Mahasiswa memperlihatkan deskripsi dari data mahasiswa itu sendiri secara lengkap, dari data pribadi hingga data yang berkaitan dengan prodinya sendiri. 


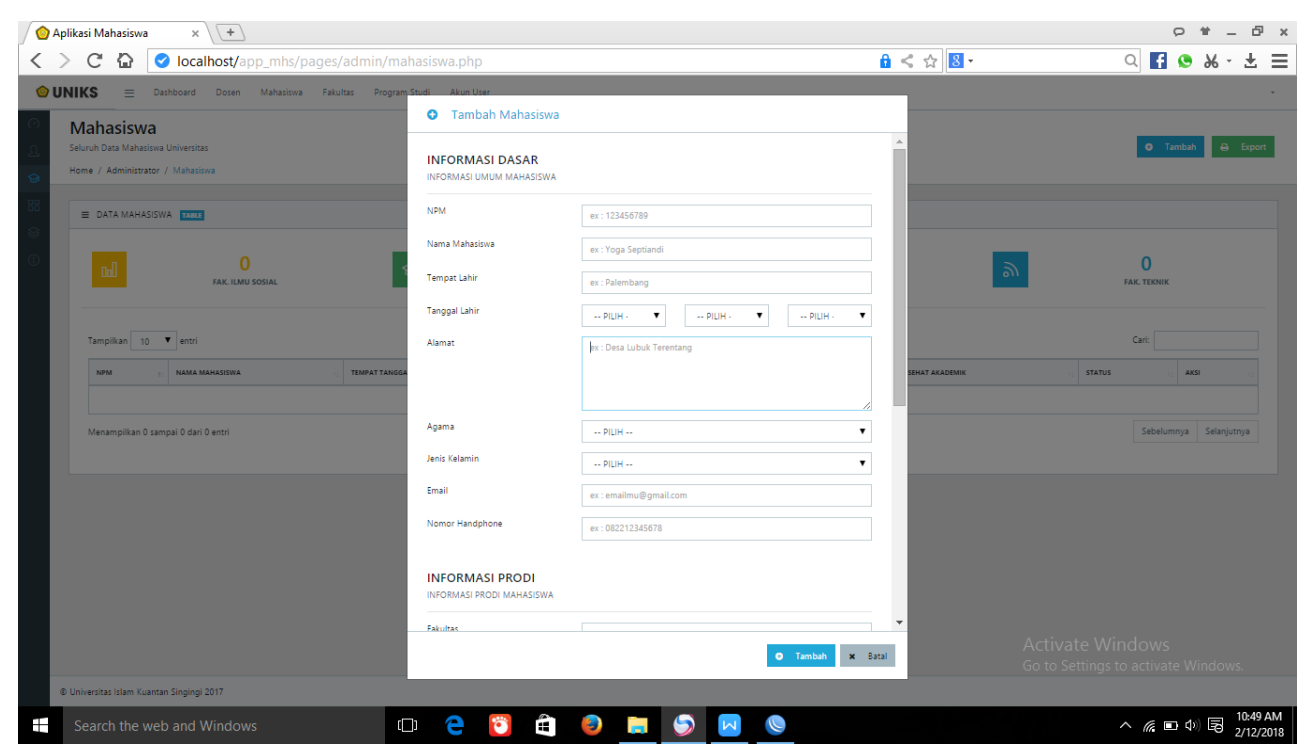

Gambar 5. Menu Entry data mahasiswa

\section{KESIMPULAN}

Dari uraian di atas, maka dapat disimpulkan bahwa :

1. Penggunaan sistem informasi data mahasiswa dan dosen mampu menyajikan data yang akurat dan terstrukur.

2. Aplikasi ini mampu memberikan kemudahan bagi Administrator (BAKASI), Dekan, dan Ketua Prodi untuk memperoleh data Mahasiswa dan Dosen secara cepat dan tepat.

3. Aplikasi ini mampu memberikan kemudahan bagi Administrator (BAKASI) dalam pelaporan kepada pimpinan Perguruan Tinggi.

\section{SARAN} berikut :

Beberapa saran yang dapat diberikan dari pembangunan sistem ini adalah sebagai

1. Pembangunan sistem ini hendaknya menggunakan keamanan sistem yang lebih secure sehingga terhindar dari ancaman dari luar.

2. Pembangunan sistem informasi ini, hendaknya disatukan dengan aplikasi akademik yang lainnya seperti KRS, KHS, E-Dom, Tracer Alumni dan lainnya. 


\section{DAFTAR PUSTAKA}

[1] S. Aswati, N. Mulyani, Y. Siagian, and A. Z. Syah, "Peranan Sistem Informasi Dalam Perguruan Tinggi," JURTEKSI-Royal-Edisi2, 2015.

[2] E. Indrayani, "Pengelolaan Sistem Informasi Akademik Perguruan Tinggi Berbasis Teknologi Informasi dan Komunikasi (TIK)," J. Penelit. Pendidik., vol. 12, no. 1, pp. 51-67, 2011.

[3] Y. Arta, "Implementasi Intrusion Detection System Pada Rule Based System Menggunakan Sniffer Mode Pada Jaringan Lokal," Inf. Technol. J. Res. Dev., vol. 2, no. 1, pp. 43-50, 2017.

[4] Jogiyanto, 2008. Sistem Teknologi Informasi. Yogyakarta : Penerbit ANDI

[5] Sutabri, Tata. 2012. Analisis Sistem Informasi. Yogyakarta : Penerbit ANDI 